\title{
Behaviour Analysis of a Cross-Girder to Tie-Girder Connection at a Road Bridge Structure
}

\author{
Mircea Suciu, Raluca Nerișanu, Delia Drăgan
}

\begin{abstract}
This paper presents several theoretical issues regarding the behaviour and calculus of the connections made with end plates and bolts, including the cover plate for the tensile stress flange. An example for calculating the hybrid connection solution is also provided, when end plates are joined together with bolts and an additional cover plate over the joint area, at the elongated flange of the girder, a solution applied for a bridge for which the feasibility study was performed.
\end{abstract}

Keywords - arch steel bridges, bolts (non-prestressed/prestressed), girder-tie connection, rigid and flexible end plate

\section{INTRODUCTION}

Similar to the connections of pipes subjected to axial stresses, also called flanges, the connections made with end plates and bolts serve at joining together beams to other forms of structural members. In the special case of steel bridges, they are used to connect the transverse girders of the deck. This is a simple and economical solution, but special care should be paid to the proper modelling of the mechanical behaviour of these connections.

When the bolts placed in the depth of the girder do not provide for the strength of the connection and the constructive system of the connection, the reinforcing placement in the slab would also be affected, one could opt for a solution with additional plates welded at both flanges and only one, welded at the tensile flange of the girder.

The present paper describes a number of theories on the behaviour and calculus of the end plate-bolt connections, as well as the joint cover plate for the tensile stress flange, the numerical analysis of the connection and applications of the solution for the structures of two bridges (one in service).

Figure 1 presents the "classical" connection made with splice plates and bolts (Fig. 1a), parallel to the end plate-based connection (Fig. 1b), [1].

A quite accurate calculus for a connection subjected to flexure, axial force and shearing force verified through experimental data, accepts that the neuter axis, respectively the rotation line, in general coincides with the compressed flange load centre, Fig. 1, on condition that a stiff grip occurs with the strong end plates.

The relationship below (1) is reached when there is an equilibrium condition between the external moment and the connection stresses:

$M=m \cdot \sum F_{b i . M} \cdot z_{b i} \quad(\mathrm{~m}-$ number of vertical rows $)$ 
a)

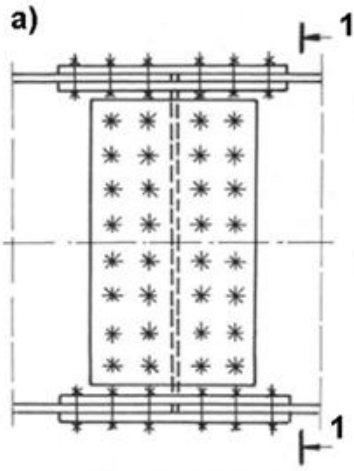

$1-1$

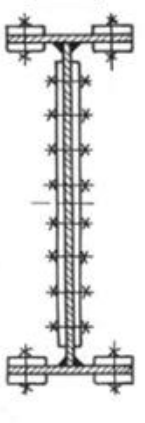

b) $2-2$

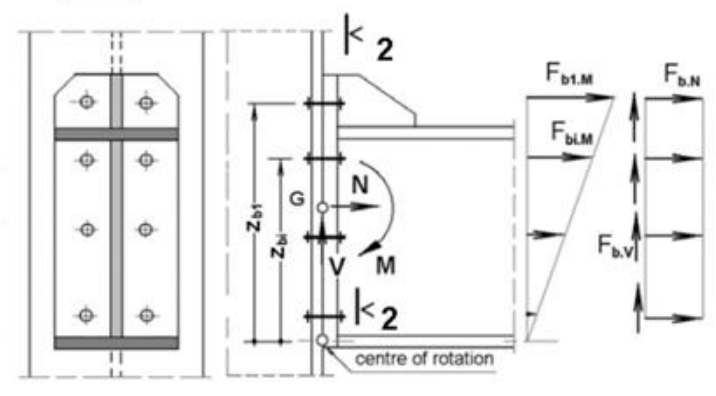

Fig. 1. Connections: a) with splice plates and bolts; b) end plate based

The tensile forces in the most tensed and farthest bolts from the connection rotation axis can be calculated with relationship (2):

$F_{b 1 . M}=M \frac{z_{b 1}}{m \cdot \sum z_{b i}^{2}}$

It is obvious that there is a uniform distribution in the connection bolts of the axial force and the shearing force (3):

$F_{b . N}=\frac{N}{n} ; F_{b . V}=\frac{V}{n} \quad(\mathrm{n}-$ overall number of bolts $)$

In order to calculate the total tensile stress (4), an addition of the maximum tensile stresses coming from the bending moment and the axial force (with their respective sign) is necessary:

$F_{t}=F_{b 1 . M}+F_{b . N}=M \frac{z_{b l}}{m \cdot \sum z_{b i}^{2}}+\frac{N}{n}$

\section{THE STRESS STATE IN TENSIONED BOLTS}

$\mathrm{T}$ The experimental measurement was conducted using GPR equipped with the antenna in the frequency range $200 \mathrm{MHz}$. The results were carried out along the road in city Tetouan as presented in the figure.

The GPR equipment employed in this study comprises a $400 \mathrm{MHz}$ transceiver (an antenna that is both the emitter and receiver of signal), a $200 \mathrm{MHz}$ transceiver, an SIR-3000 GPR data control and recording system, and a survey wheel for measuring distance, all from Geophysical Survey Systems International (GSSI) [10-13].

In Fig. 2, [8] there is given the mechanical behaviour of a flange-type connection, made with usual bolts subjected to tension, and where the end plates (flanges) are supposed to have a very high stiffness.

When no prestressing and no compression force are present on the contact surfaces, the external tensile force $\mathrm{F}_{\mathrm{t}}$ applied to the connection will be transferred to the bolts through forces $F_{b}$. Consequently, the change in the tensile force $F_{t}$ will be followed by the change of the forces in the bolts and a relative displacement of the end plates (flanges) will occur at the same time. 

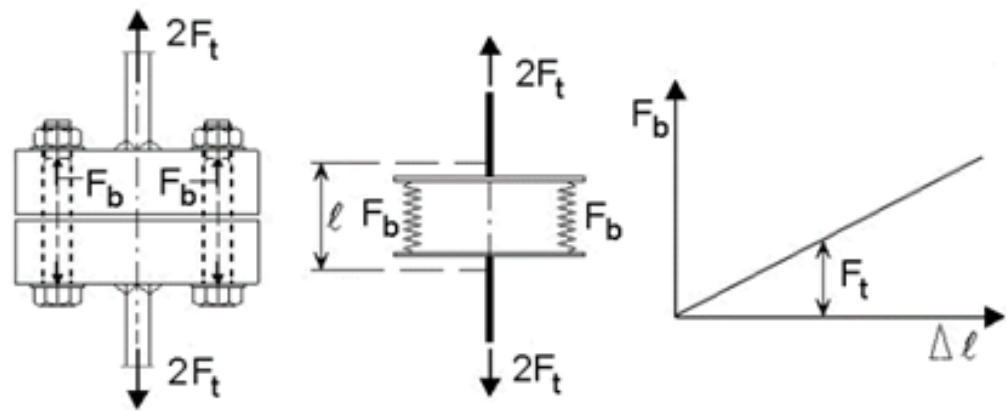

Fig. 2. Behaviour of a flange connection with common bolts

When prestressed with a force $F_{v}$, this force will initially be in equilibrium with the compression force exerted at the contact surface, $\mathrm{F}_{\mathrm{c}}$. The two flanges will act as a monolith part as long as the external force $F_{t}$ is smaller than the prestressing force $F_{v}$.

When an external force is applied, the stresses in the bolts will be modified to a very small extent (it is supposed that flanges present a high stiffness because of the large area, by comparison with the bolt area), Fig. 3, [5].

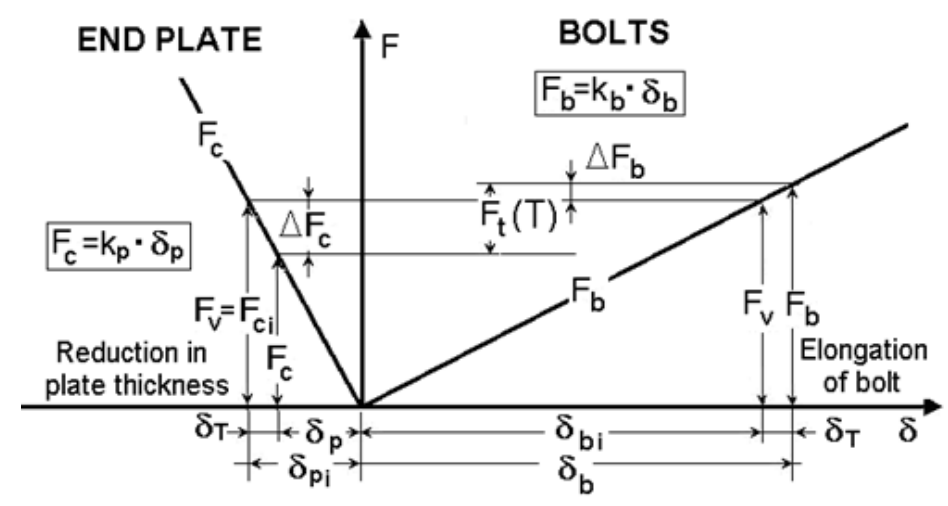

Fig. 3. Forces in prestressed fastener

As seen in Fig. 3, the application of an external force $F_{t}$ leads to a significant change of the compressive stress in the end plate, of value $\Delta \mathrm{F}_{\mathrm{c}}$, compared to the increase of the tensile stress in the bolts $-\Delta \mathrm{F}_{\mathrm{b}}$.

In the condition of an elastic behaviour of the connection, the plate is separated when $F_{c}=0$, for an external force of magnitude:

$F_{t}^{s e p}=F_{v}\left(1+\frac{k_{b}}{k_{p}}\right)$

In practical design cases, ratio $\mathrm{k}_{\mathrm{b}} / \mathrm{k}_{\mathrm{p}}$ ranges in value between $0.05 \ldots 0.12$, if the end plates are very thick, and it yields:

$F_{t}^{s e p}=(1.05 \ldots 1.12) \cdot F_{v}$

If the plates are stiff, after the separation of the end plates, the stress in the bolts will be equal to the external tensile stress $F_{t}$. 
At the same time, the position of the parts contact area should be taken into consideration; this aspect is shown in Fig. 4, [8], where the end plate thickness is much diminished as compared to previous cases.

When the contact is made in the middle, Fig. 4a, the situation for stiff end plates or flanges is presented. When the parts contact is performed externally, Fig. 4.b, we have the case of flexible end plates. In this latter case, an increase in the external tensile force will modify the stress in the bolts with about the same magnitude.

The relationship of the forces is illustrated in Fig. 4.c, d, [6], [8].

a)

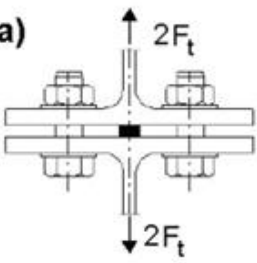

c)

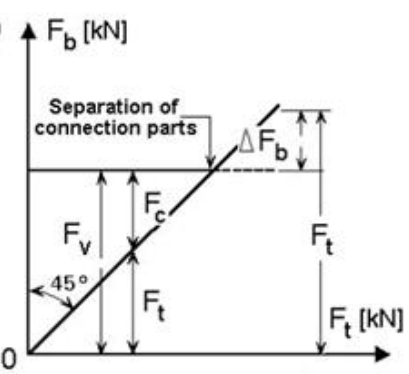

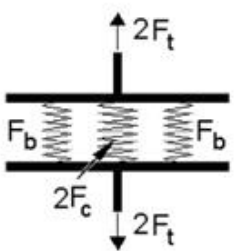

d)

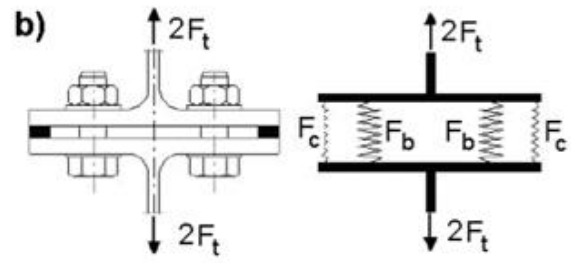

d)

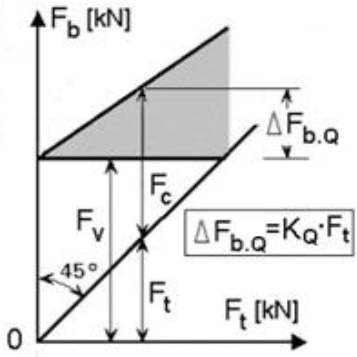

Fig. 4. Effect of the location of the contact pressure on the bolt force

\section{HYBRID END PLATE AND SPLICE STRIP CONNECTIONS}

When the bolts placed on the girder depth do not provide for the strength of the connection and the development of the end plate beyond the girder cross section could affect the constructive solution in the connection area, one can opt for a solution in which additional cover plates are welded to both flanges or only one plate is welded to the tensed girder, Fig. 5.
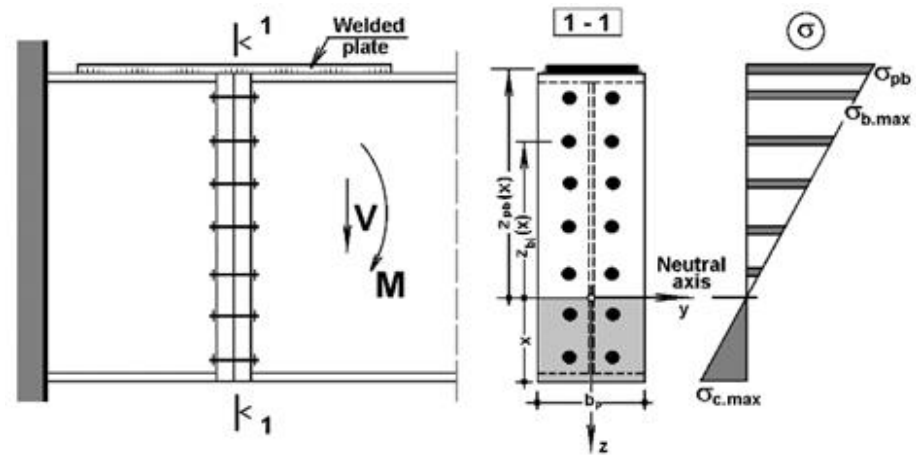

Fig. 5. Connection made with an end plate and a strip welded to the elongated base 
The position of the neuter axis is found by making the static moment of the compressed surface equal to the static moment of the tensile members:

$\frac{1}{2} b_{p} x^{2}=A_{p b} z_{p b}(x)+2 \sum_{1}^{n_{t}} A_{b} z_{b i}(x) \Rightarrow x$

Knowing the position of the neuter axis, one can calculate the stresses with the Navier equation:

$\sigma_{b i}=\frac{M_{E d}}{I_{p . b}} z_{b . i}$

\section{Verification of the connection elements}

In accordance with EC3-1-8, [7], the bolt connections subjected to tension are calculated in one of the following ways, as per category:

\section{Not prestressed D category bolts}

In this category, one uses bolts belonging to quality grades 4.6 up to 10.9 inclusively.

In the area of the joint between the end plates, bolts are verified through the relationship of interaction between the moment and shearing force, in accordance with EC3$1-8$ :

$\frac{F_{V . E d}}{F_{V . R d}}+\frac{F_{t . E d}}{1.4 \cdot F_{t . R d}} \leq 1$

where: $F_{V . E d}=\frac{V_{E d}}{n_{b}} ; F_{t . E d}=\sigma_{b . \max } \cdot A_{b} ; F_{V . R d}=\frac{\alpha_{v} f_{b} A_{b}}{\gamma_{M 2}} ; F_{t . R d}=\frac{0.90 f_{u b} A_{s}}{\gamma_{M 2}}$

Prestressed E category bolts

In this category, one includes bolts from quality grades 8.8 and 10.9, with controlled tightening, according to the Reference Standards.

The theoretical resistance to sliding of a prestressed bolt from grade 8.8 or 10.9 is calculated with:

$F_{\text {s.Rd }}=\frac{k_{s} n \mu}{\gamma_{M 3}} F_{p . C}$

where: $\mathrm{k}_{\mathrm{s}}$-function of the hole type; $\mathrm{n}$ - number of friction surfaces; $\mu$ - friction coefficient.

The calculated prestressing force is assessed with relationship:

$F_{p . C}=0.7 f_{u b} A_{s}$

The theoretical shearing force in the limit state of normal service should not exceed the calculus resistance to sliding.

The ultimate theoretical shearing force should not also exceed the bearing pressure resistance to the hole.

For $\mathrm{C}$ grade connections, the theoretical resistance to the sliding of a bolt is found with relationship:

$F_{s . R d}=\frac{k_{s} n \mu}{\gamma_{M 3}}\left(F_{p . C}-0.8 F_{t . E d}\right)$ 


\section{NUMERICAL EXAMPLE}

The present application makes an analysis of the state of stresses from the connection of a cross-girder to the girder-tie of a road bridge with the structure on steel arches.

The steel girders are made from steel grade S355M: $f_{y}=355 \mathrm{~N} / \mathrm{mm}^{2} ; f_{u}=470 \mathrm{~N} / \mathrm{mm}^{2}$.

The bolts to be used are M 27 - group 10.9, with the calculated characteristics:

$f_{y b}=900 \mathrm{~N} / \mathrm{mm}^{2} ; f_{u b}=1000 \mathrm{~N} / \mathrm{mm}^{2} ; A_{s}=4.59 \mathrm{~cm}^{2} ; A_{b}=6.16 \mathrm{~cm}^{2}$.

The theoretical stresses in the connection, for the bending moment and shearing force compatible with those for a road bridge of span $48.00 \mathrm{~m}$, of two lanes and sidewalk supports with bicycle lanes of $4.00 \mathrm{~m}$, are:

$$
M_{E d}=1400 \mathrm{kNm} ; V_{E d}=1050 \mathrm{kN} .
$$

The calculus is developed in the following hypotheses:

- E1 - connection with rotation stiff end plates and an additional cover plate over the joint area, at the elongated base of the girder;

- E2 - connection with rotation flexible end plates and an additional cover plate over the joint area at the elongated base of the girder.

The constructive scheme of the connection is presented in Fig. 6 .

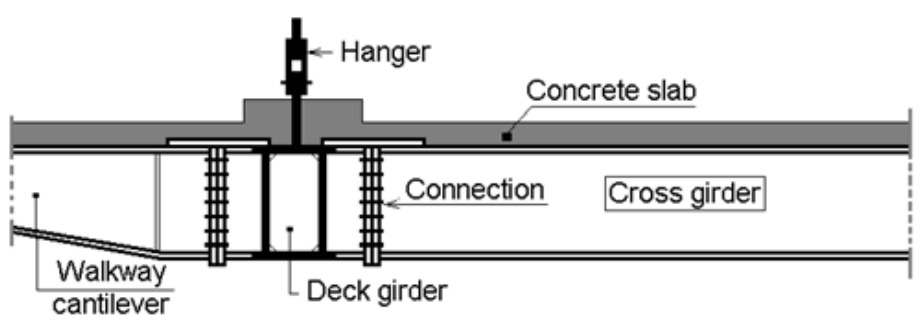

$M_{E d}=1400 \mathrm{kN} \cdot \mathrm{m}$

$V_{E d}=1050 \mathrm{kN}$

Fig. 6. The constructive scheme of the connection and calculated stresses

E1 - Connection with rotation stiff end plates and an additional cover plate over the joint area, at the tensed base of the girder

The constructive scheme of the connection and the stress assessment diagram is given in Fig. $7 \mathrm{a}$.

\section{E2 - Connection with rotation flexible end plates and an additional cover plate at the tensed flange of the girder}

The constructive scheme of the connection and the stress assessment diagram is given in Fig. 7b. The neuter axis position is found, as in $x=z_{p}=21.3 \mathrm{~cm}$.

Table 1 presents the main forces of connection and the stress degree coming from the interaction relationship $\mathrm{M}-\mathrm{V}$, for the two calculation methods. 

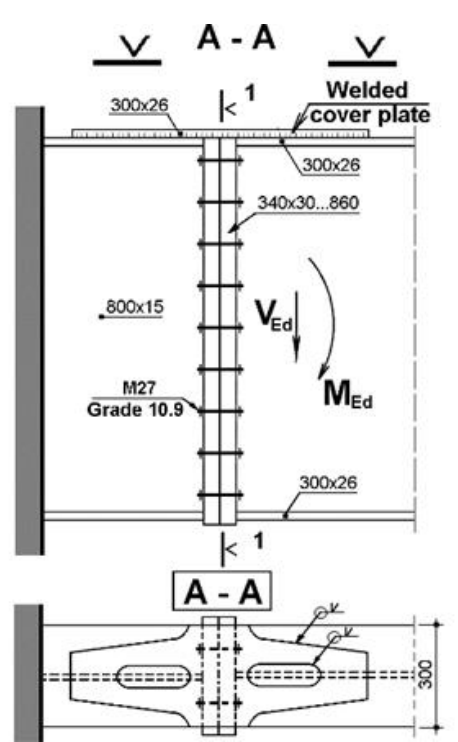

a)

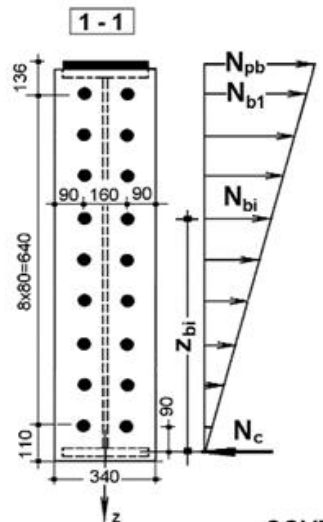

b)

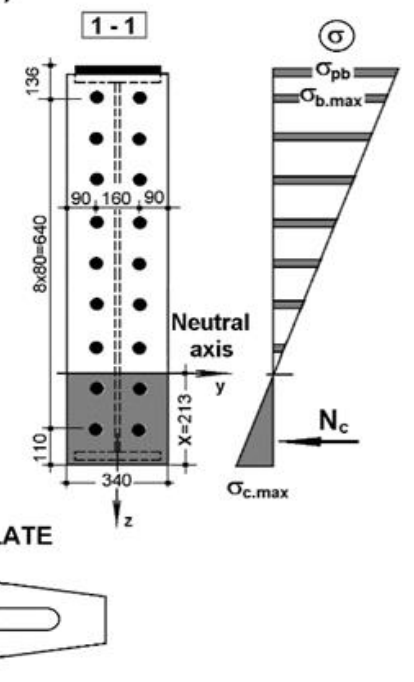

Fig. 7. Connection with end plates and additional cover plate to the tensed flange a) rotation stiff end plates; b) rotation flexible (semi-rigid) end plates

Table. 1. Main forces of connection and stress degree.

\begin{tabular}{|c|c|c|}
\hline Forces in connection & E1 & E2 \\
\hline $\begin{array}{c}\text { Stresses in cover plate } \\
\sigma_{p b}\left[\mathrm{daN} / \mathrm{cm}^{2}\right]\end{array}$ & 583 & 1688 \\
\hline $\begin{array}{c}\text { Maximum force tensile in bolts } \\
N_{b . \max }[\mathrm{kN}]\end{array}$ & 194.7 & 84.8 \\
\hline$\frac{F_{V . E d}}{F_{V . R d}}+\frac{F_{t . E d}}{1.4 \cdot F_{t . R d}}$ & 0.66 & 0.42 \\
\hline
\end{tabular}

\section{CONCLUSIONS AND DESIGN RECOMMENDATIONS}

The connections made with end plates and bolts can be used for steel bridges to connect the deck girders leading to simple and economical constructive solutions on condition that the mechanical behaviour of the connections is properly modelled.

The positioning of a cover plate on the tensed base of the girder substantially improves the general behaviour of the connection as stresses in the joint area are made uniform and big stresses in the bolts are transferred to the added cover plate.

The cover plate should be welded to the base only after all the bolts in the connection are well tightened.

The prestressing of the end plate gripping bolts is not necessary and consequently is not recommended in the case of such connections; to provide a perfect contact between the end plates, we recommend to tighten the bolts at a stress value of $10 . .20 \%$ from the theoretical prestressing stress value.

When bolts that are previously subjected to traction from external loads are prestressed, an additional load of $5 \ldots 12 \%$ is recommended, if the tensile stress does not exceed the prestressing force and only for stiff end plates. 


\section{sciendo}

40 Ovidius University Annals Series: Civil Engineering, Year 22, 2020

The design norms and the literature do not provide a relatively simple and practical methodology to evaluate the end plates stiffness.

Figure 8.a presents an arch steel bridge crossing the Someș River in the city of ClujNapoca [9], for which a feasibility study was performed and Fig. 8.b shows the bridge over the Cibin river in the city of Sibiu, in service now [2], [3]. For these bridges the solution of connecting with end plates and cover plates at the tensed upper flange was used.

In paper [4] is presented more information about the connection of the type shown in this paper.
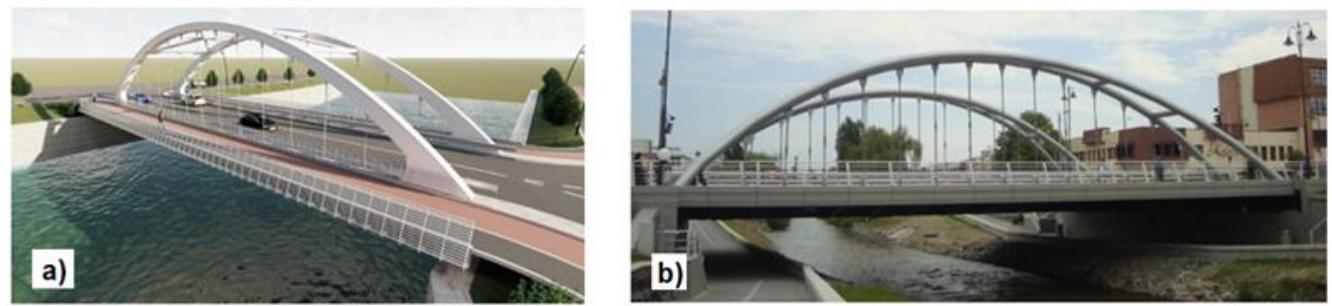

Fig. 8: a) Bridge crossing Someş river in Cluj-Napoca. Feasibility study [9], [4]

b) Bridge over Cibin river in Sibiu [9]

\section{REFERENCES}

[1] Moga P. (2018), Euronorme. Calculul elementelor metalice., Ed. U.T. PRESS, Cluj-N. [2] Guţiu Ş. I., Moga P., Moga C., Danciu A. (2016), The new arch bridge in the city of Sibiu, Romania, The $9^{\text {th }}$ International Conference "Bridges in Danube Basin", published in "Procedia Engineering 156" ELSEVIER, pag. 132-139

[3] Iliescu M., Guţiu Ş. I., Moga C. (2017), Technological Problems regarding the Design and Execution of the new Bridge over Cibin River in the City of Sibiu and the Bridge Impact in Reducing Pollution in the City Center Area, $10^{\text {th }}$ International Conference Interdisciplinarity in Engineering, INTER-ENG 2016, Book Series: Procedia Engineering,Volume: 181, published: 2017, pag. 20-27

[4] Moga C., Suciu M., Drăgan D., Nerișanu R. (2019), Efficient connection of cross girders of arch steel road bridges. Buletinul Institultului Politehnic Iași. Vol. 65 (69). Nr. 2, pag. 45-64

[5] Kulak G. L., Fisher J. W., Struik J. H.A. (2001), Guide to Design Criteria for Bolted and Riveted Joints. AISC

[6] *** Design of structural connection to Eurocode 3. Leonardo da Vinci Project. 2003

[7] ***SR EN 1993-1-8/2006. Eurocod 3: Proiectarea structurilor de oţel. Partea 1-8

[8] European Steel Design Education Programme. ESDEP., The ESDEP Society

[9] *** Proiecte realizate de XC PROJECT și SC DRUMEX din Cluj-Napoca

Note:

Raluca Nerișanu- Technical University of Cluj-Napoca, 28 Memorandumului Street, 400114-ClujNapoca, Romania (corresponding author to provide phone: +40-728-671024; e-mail: Raluca.Nerisanu@cfdp.utcluj.ro).

Mircea Suciu- Technical University of Cluj-Napoca, 28 Memorandumului Street, 400114-Cluj-Napoca Romania (e-mail: Mircea.Suciu@cfdp.utcluj.ro).

Delia Drăgan- Technical University of Cluj-Napoca, 28 Memorandumului Street, 400114-Cluj-Napoca, Romania (e-mail: Delia.Dragan@ cfdp.utcluj.ro). 